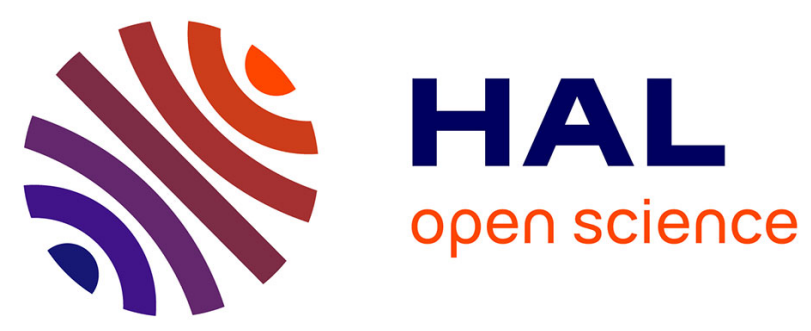

\title{
Towards a Metamodel supporting E-government Collaborative Business Processes Management within a Service-based Interoperability Platform
} Andrea Delgado, Daniel Calegari, Laura González, Aurelie Montarnal, Frederick Benaben

\section{To cite this version:}

Andrea Delgado, Daniel Calegari, Laura González, Aurelie Montarnal, Frederick Benaben. Towards a Metamodel supporting E-government Collaborative Business Processes Management within a Servicebased Interoperability Platform. HICSS 2020 - 53rd Hawaii International Conference on System Sciences, Jan 2020, Hawai, United States. p. 2019-2028. hal-02933022

\section{HAL Id: hal-02933022 \\ https://imt-mines-albi.hal.science/hal-02933022}

Submitted on 8 Sep 2020

HAL is a multi-disciplinary open access archive for the deposit and dissemination of scientific research documents, whether they are published or not. The documents may come from teaching and research institutions in France or abroad, or from public or private research centers.
L'archive ouverte pluridisciplinaire HAL, est destinée au dépôt et à la diffusion de documents scientifiques de niveau recherche, publiés ou non, émanant des établissements d'enseignement et de recherche français ou étrangers, des laboratoires publics ou privés. 


\section{Towards a Metamodel supporting E-government Collaborative Business Processes Management within a Service-based Interoperability Platform}

\author{
Andrea Delgado, Daniel Calegari, Laura González \\ Universidad de la República, Uruguay \\ \{adelgado, dcalegar, lauragon\} @ fing.edu.uy
}

\begin{abstract}
Interoperability between different organizations is a complex task, where a key element is to be able to define without ambiguity the concepts that are involved in each domain and their relations. A key aspect for enabling e-government is the technological support for complex interaction scenarios, defining collaborative Business Processes (BPs) that are the basis for these interactions. E-government collaborative BPs involve several and heterogeneous participants: organizations, partners, and users, with different capabilities, needs, and available technical support. The goal of this paper is to present ongoing research on e-government cross-organizational collaborative BPs support in a service-based interoperability platform. This proposal is focused on the formalization and exploitation of e-government knowledge and information (i.e., metamodels and ontologies) to improve the definition, automated generation, control, monitoring and improvement of e-government collaborative BPs.
\end{abstract}

\section{Introduction}

Organizations are usually forced to collaborate with partners and clients to enhance the services and products they deliver. Their interoperability depends on the definition of the concepts that are involved in each domain and their relations. The e-government domain has its own particularities since its main focus is citizens and its main objective the provision of services to allow them to interact with public organizations.

Being nowadays the internet access all over the world almost $57 \%$ of the total population (4.383.810,324 ${ }^{1}$ ) with penetration of almost 90\% in North America and Europe and almost 70\% in Latin America, governments have to seize the opportunities to serve citizens within e-government solutions increasingly sophisticated. Complex

\footnotetext{
${ }^{1}$ https://www.internetworldstats.com/stats.htm
}

Aurélie Montarnal, Frédérick Bénaben

IMT Mines Albi, France

\{aurelie.montarnal,frederick.benaben\}@ minesalbi.fr interaction scenarios for e-government usually comprise collaborative Business Processes (BPs) [1] involving heterogeneous participants: organizations (employees, technologies), partners (providers, consumers), and users (citizens, foreigners), with different capabilities, needs, and available technical support. We can identify two main types of interaction scenarios for e-government analysis models [1]: (i) closed, in which interactions between organizations are explicitly defined and agreed as collaborative BPs; or (ii) open in which organizations offer capabilities for integration, not explicitly agreeing on their BPs but mainly on the contract of the capabilities they provide or require to be able to participate in the collaboration. Capabilities for payment, event awareness, security, process monitoring and analysis, open data, integration with social networks, prediction, among others, present relevant issues to tackle within e-government support.

Business Process Management (BPM) [2, 3] provides support for the complete lifecycle of BPs, from modeling to execution and analysis, to guide the efforts organizations carry out to drive their business based on the underlying processes they perform. An issue is the definition of choreographies that organizations are willing to agree on, to perform the process within each one of them. This is a challenge when organizations present different maturity levels for dimensions such as their infrastructure, available technologies and explicit knowledge of their BPs (i.e., specification of their BPs in a suitable modeling language such as BPMN 2.0 [4]).

In previous works, we have presented the support for cross-organizational collaborative BPs based on two approaches: (i) a Process-Aware Inter-organizational Service-Based Interoperability Platform (PA-IOSIP) [1] which includes a BPMS on top of an integration platform that is defined in the e-government context of Uruguay, also providing in [5] an architecture vision linking BPs and services, and (ii) a Mediation Information System (MIS) [6, 7] that provides support for collaborative BPs that are generated automatically in the context of crisis management systems in France. 
The goal of this paper is to present advances of an ongoing research effort on e-government cross-organizational collaborative BPs support in a service-based interoperability platform. It is focused on the formalization and exploitation of e-government knowledge and information to improve the definition, automated generation, control, monitoring and improvement of e-government collaborative BPs. Our roadmap involves integrating existing knowledge and previous results from each participant research group, generating a more complete, integrated and robust proposal. We identified the following objectives:

(O1) Generate a state of the art of existing approaches to deal with e-government complexity.

(O2) Define a model-driven approach for specifying e-gov information supporting the whole approach.

(O3) Integrate existing results and platforms from partners providing support for collaborative BPs and services execution, in a distributed environment, also allowing collaborative BPs discovery and conformance checking based on services and logs execution information.

(O4) Evaluate the ideas through a case study of a real collaborative $\mathrm{BP}$ and find improvement opportunities.

In this paper, we focus on providing advances related to objective $(\mathrm{O} 2)$ and $(\mathrm{O} 3)$, as well as a first validation $(\mathrm{O} 4)$ of the metamodeling perspective related to objective $(\mathrm{O} 2)$. Although we introduce related work, full coverage of objective $(\mathrm{O} 1)$ is part of further work.

The rest of the paper is organized as follows: Section 2 presents the main concepts, as well as previous and related works. Section 3 describes the advances in the research effort, and Section 4 presents an initial validation of the main ideas using a case study from the Uruguayan e-government platform. Finally, Section 5 presents conclusions and an outline of future work.

\section{Existing knowledge}

Integrating knowledge and information about the context domain (i.e., e-government) in an interoperability platform allows participants to connect their solutions to the software provided by the platform, more easily. Previous works from the authors have dealt with ontologies and metamodels for crisis management, interoperability platforms definition, collaborative processes modeling and execution in BPMS platforms, process-aware information systems, and e-government solutions. In the following sections, we present the context of the proposal and the case study defined.

\subsection{Context of the proposal}

To ensure interoperability across heterogeneous partners through cross-organizational collaborative processes, it is necessary for them to share a common framework. As such, a core collaborative metamodel has been defined to support inter-organizational collaborations whichever the field of application.

Figure 1 shows the core metamodel and its five main parts: (I) the Context System (light grey) includes components and characteristics of the considered environment and the opportunities/threaten linked, (ii) the Objective System (medium grey) aims at defining the objectives that should be reached to resolve the crisis, (iii) the Partner System describes the potential stakeholders of the collaboration, (iv) the Behavior System (dark grey) is dedicated to the collaborative process to be orchestrated and (v) the Performance System (white) assess the overall performance of the collaboration by comparing through dedicated Key Performance Indicators (KPIs) the performance objective to the measures on the field. Then, this core metamodel can be specialized in specific business field collaborations. As a first iteration, it has been extended to a crisis management layer. The further objective here is to provide a new extension to the core metamodel with a layer dedicated to the e-government domain.

In addition, a whole Mediation Information System (MIS) has been developed based on this metamodel and allows organization to support their cross-organizational collaborations through three main parts: the characterization of collaborative situations via the use of modelers based on the adapted metamodel (i.e., one extension of the core metamodel), the deduction of collaborative BPMN 2.0 inter-organizational processes to achieve the objectives of the collaboration and, on run-time, the detection of variation between the expected and the real situation and on-the-fly adaptation of the collaborative process.

Another vision, closely related to this, is taken for the definition and construction of such a collaborative platform, which in initial version that was based mostly on middleware concepts and tools for interoperability, and now is in a process of extension using concepts and tools for collaborative processes upon the already defined ones. The reference architecture we envision adds support for collaborative BPs to the existing infrastructure by adding a BPMS on top of the integration platform. The BPMS can then be seen as a mediator system executing collaborative processes defined in the choreographies that were agreed by organizations, interacting with their existing systems or BPMS in each organization. 


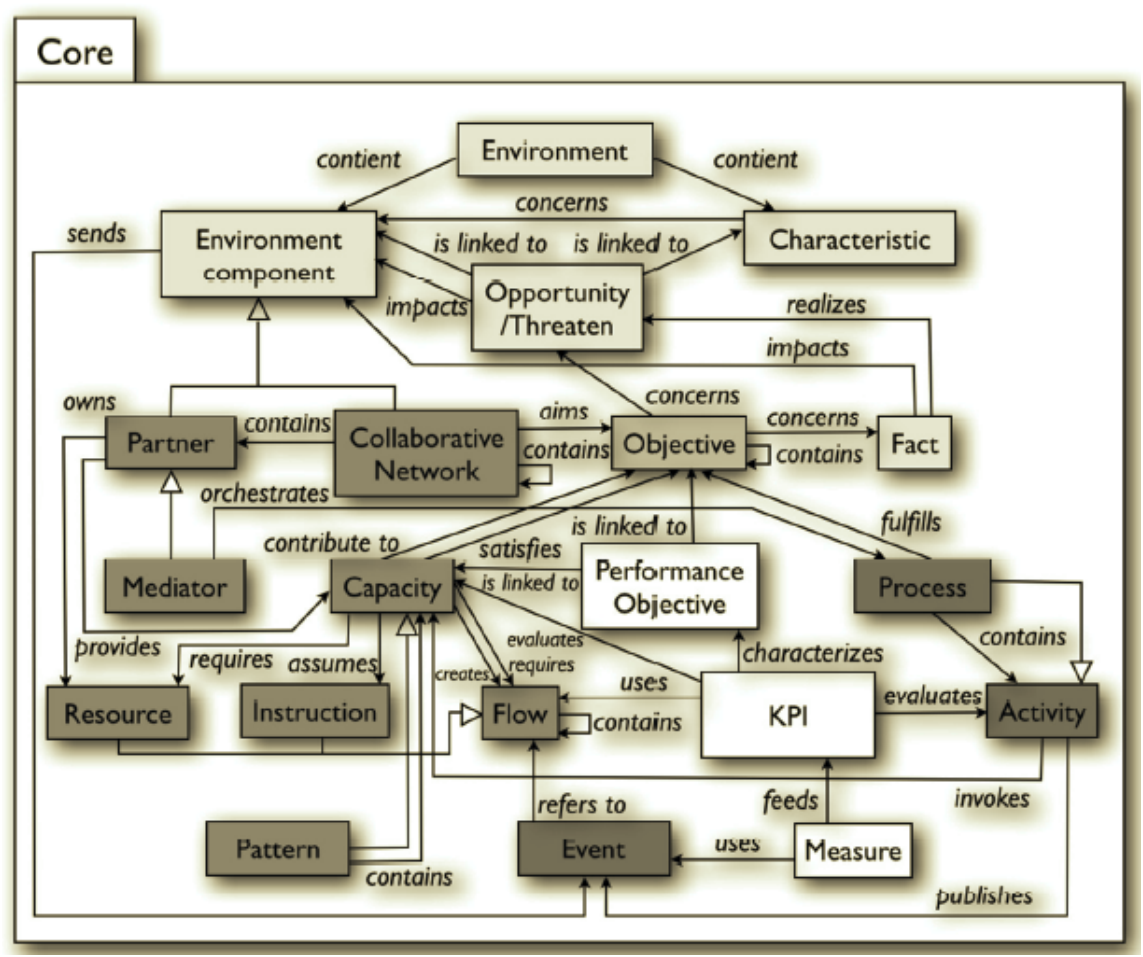

Figure 1. Core collaborative metamodel to support inter-organizational collaborations from [6]

The proposed PA-IOSIP reference architecture defines three main layers: user applications layer, BPMS layer, and integration layer. The User applications layer's aims to provide the user with several applications to interact with the BPs executing in the integration platform, and also with other components such as documents and business rules. The BPMS layer provides components to support the complete BPs lifecycle including modeling, implementing, executing, evaluating and improving processes. Finally, the integration layer aims to facilitate an interoperable cross-organizational collaboration by providing several components that process inter-organizational interactions. In particular, it has a middleware platform, based on an Enterprise Service Bus (ESB) and Complex Event Processing (CEP) technologies, which provides different types of integration capabilities.

\subsection{Uruguayan e-Government Platform}

The Uruguayan e-Government Platform (PGE) provides the legal and technical environment, as well as the required technological resources, to facilitate the deployment of e-government applications and services within the Uruguayan State [8]. The PGE includes an Interoperability Platform (Plataforma de Interoperabilidad, PDI) as well as a Citizens Portal, and it was developed by the Uruguayan e-Government Agency (Agencia de Gobierno Electrónico y Sociedad de la Información y del Conocimiento, AGESIC).

The PDI enables and facilitates government organizations to offer their business data and functionality via a service-oriented approach [9]. Organizations use the Web Services technology to offer business services, which are usually hosted on organizations' infrastructure. These services are exposed and invoked through proxies deployed on the PDI which, in this way, can process all service invocations and apply them mediation operations (e.g., security, routing, transformation). The Citizens Portal enables citizens to access e-government applications, services, and procedures, e.g., a citizen can get a response from a service provided by a government organization and can start a multiorganizational e-government procedure. Figure 2 shows a sketch of how the PDI positions as an intermediate processing layer for invoking e-government services.

Since its start-up in 2009, government organizations have been progressively joining the PDI and exposing business services through the platform. As listed in the PDI service catalogue $e^{2}$ there are currently more than seventy business services provided.

\footnotetext{
${ }^{2}$ https://www.gub.uy/agencia-gobierno-electronico-sociedadinformacion-conocimiento/tematica/catalogo-pdi
} 


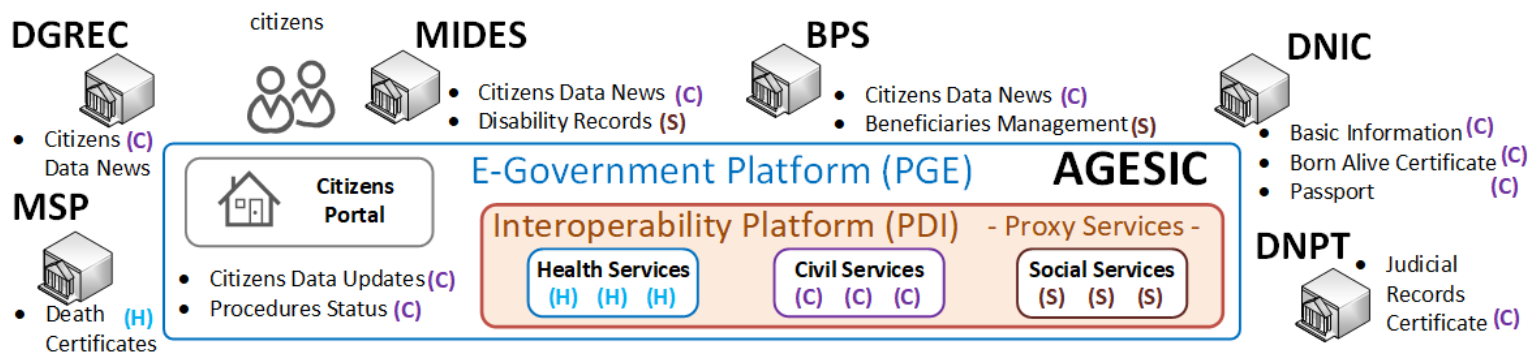

Figure 2. Uruguayan Interoperability Platform (PDI) for inter-organizational collaborative processes from [10]

Some of the government organizations that are currently integrated in the PDI are the Ministry of Public Health (MSP), the Ministry of Social Development (MIDES), the Civil Identification National Directorate (DNIC), the Civil Status Registry General Directorate (DGREC), the Social Security Institute (BPS) and the Technical Police National Directorate (DNPT). Among others, they provide health-related services (e.g., Death Certificates), civil-related services (e.g., Basic Information, Judicial Records Certificate), social-related services (e.g., Disability Records).

It is important to note that other government initiatives leverage interoperability platforms using a similar approach to the one followed in Uruguay, e.g., the Platina platform of Andalucía $^{3}$, and the interoperability platforms of Perú ${ }^{4}$ and Ecuador ${ }^{5}$.

\subsection{Related work}

There are several works on the conceptualization of e-government [1, 11, 12]. Most studies focus on providing solutions that include technical aspects (architectures and platforms), procedures and regulations for e-government actors, such as businesses, organizations, and citizens. They also provide reports on case studies of the application of the approaches to specific contexts in different countries. To the best of our knowledge, none of them propose, us we do, to use the e-government metamodel and ontologies to generate choreographies that are orchestrated in a central platform as collaborative BPs. Due to space restrictions, a systematic review of models to conceptualize e-government is part of further work.

In [10] the authors present an in-depth analysis of existing interoperability platforms and compliance management requirements. Regarding architectural proposals, the review in [13] presents examples of seven architectures concluding that the organization

\footnotetext{
${ }^{3}$ http://www.juntadeandalucia.es/servicios/madeja/contenido/recurso/19

${ }^{4}$ https://www.gobiernodigital.gob.pe/interoperabilidad/

${ }^{5}$ http://www.geoportaligm.gob.ec/portal/?wpfb_dl=231
}

in three layers, the use of WS and workflows, and sending notifications to citizens are key elements to provide in an e-government solution. Also, several architecture attributes are identified such as "Interoperability and integration", "Security and trust", "Traceability", "Cross-border characteristics", among others, that we provide in our approach. In [14] also a layering approach is taken to define a framework (and meta-model) which includes business models for developing e-government strategies with a focus on BPs and information systems. Unlike our proposal, they do not present a formal meta-model diagram with the concepts and relationships identified.

Finally, in $[15,16]$ the authors propose and analyze the use of ontologies for e-government, identifying several concepts and relationships. In particular, $[17,16]$ presents a meta-model for public services with some concepts similar to ours but with a narrower focus, since it does not model all elements involved in e-government interactions and collaborative BPs as we do.

\section{Towards an integrated vision}

In what follows we present advances concerning the definition of a model-driven approach for specifying e-gov information $(\mathrm{O} 2)$ and the integration of existing results and platforms from partners providing support for collaborative BPs in an e-gov context (O3), which is strongly based on the existence of a core metamodel for e-gov $(\mathrm{O} 2)$.

\subsection{Metamodel for e-government}

We analyzed the concepts and relationships that are involved in an e-gov context and defined a metamodel providing a high-level perspective, which is depicted in Figure 3. The metamodel needs to be refined and integrated with the core collaborative metamodel, as will be described in Section 3.2. Many kinds of actors participate through the e-government PDI: users that can be citizens or foreigners, and organizations that 
can be public (e.g., MSP) or external (private ones or from other countries). These actors consume services that are also provided by actors: individual users can provide human services (e.g., medical consultation with a doctor) whilst organizations usually provide automated services. Services in public organizations are categorized as shown in Figure 2.

Actors participate in e-government processes (some of them collaborative) that use services actors provide. Processes arise from an organizational vision from which specific goals are defined. Those goals are also the source of many outcomes, that can take the form of a service that an organization provides. Finally, many governmental regulations generate compliance requirements, requiring preconditions to be taken into account when using services within those business processes (e.g., a certificate must be issued before proceeding with the process).

The metamodel provides a high-level perspective that can be refined, or connected with other languages, for many purposes, e.g., automation and knowledge management. In particular: business process aspects can be described based on the Business Process Model and Notation (BPMN [4]); service descriptions can be based on the Service-oriented architecture Modeling Language (SoaML [18]); organizational aspects can be refined based on the Business Motivation Model (BMM [19]) and SoaML; and business rules related to compliance requirements can be described using the Decision Model and Notation (DMN [20]). Collaborative BPs in e-government scenarios have to comply with compliance requirements originating from different types of sources (e.g., laws, agreements, standards). In order to address this issue, the metamodel described in Section 3.1 can be extended with compliance requirements related concepts as proposed in [21] and presented in Figure 4.

Compliance Requirements represent requirements that can be applied to different objects of the same type (e.g., availability of service greater than 90\%). A compliance requirement is based on a compliance control (e.g., availability of service greater than a percentage value) and defines a value for all its configuration properties (e.g., percentage value $=90 \%$ ). Compliance Profiles group compliance requirements for the same object type (e.g., service). Compliance Object Types represent the types of objects that are the target of compliance control (e.g., service, operation, BP). Compliance Areas represent broad areas of compliance (e.g., quality of service) and comprise Compliance Dimensions, which capture a high-level compliance facet (e.g., performance). Compliance Factors represent a particular aspect of a dimension (e.g., response time).

\subsection{Integration with the core metamodel}

As a first step on the refinement of the e-government metamodel, we can integrate it with the CORE metamodel depicted in Figure 1. In [6] the CORE metamodel was extended with four packages containing concepts dedicated to a crisis. The basic principle is based on the fact that the CORE metamodel has been defined to model any collaborative situation in a very superficial manner. However, the CORE metamodel has also been defined to be easily extended with new domain-specific packages. These packages should be dedicated to cover (at least one of) the partner, context, objective and behavior dimensions with new domain-specific concepts.

One major constraint is that these new concepts must imperatively inherit from concepts from the CORE metamodel (or potentially from other concepts of another domain-specific package, as soon as these other concepts are in an inheritance chain that ends to concepts of the CORE metamodel). This inheritance mechanism to extend the CORE metamodel is crucial because it is the way to extend the modeling capability of the approach and to refine the precision of the models. We believe that we could base our extension on this work since several concepts already presented in the CORE metamodel or the crisis management extension could be useful for representing our e-government layer. This extension is depicted in Figure 5 and briefly explained next:

- Partner package expresses the different resources and know-how of the partners. This could be adapted to include our specific vision of partners in e-gov: the hierarchy of e-government actors, and specific services. As an example, instead of having an "Actor on Site" and a specific "Actor service", representing a crisis management service provided by a human actor, we can have a "Public" and an "Automated" service, representing a service provided by a public organization (as described in Section 2.2). Moreover, service and organization categories, as well as dependencies between services (relating preconditions and outcomes) could also be represented within this package.

- Context package includes components and characteristics of the considered environment, and also opportunities or threats specific to these environmental characteristics. In our case, these aspects are not always considered for business processes. Nevertheless, some territorial aspects could be present, e.g.: for representing tax exemption in a certain region. Moreover, 


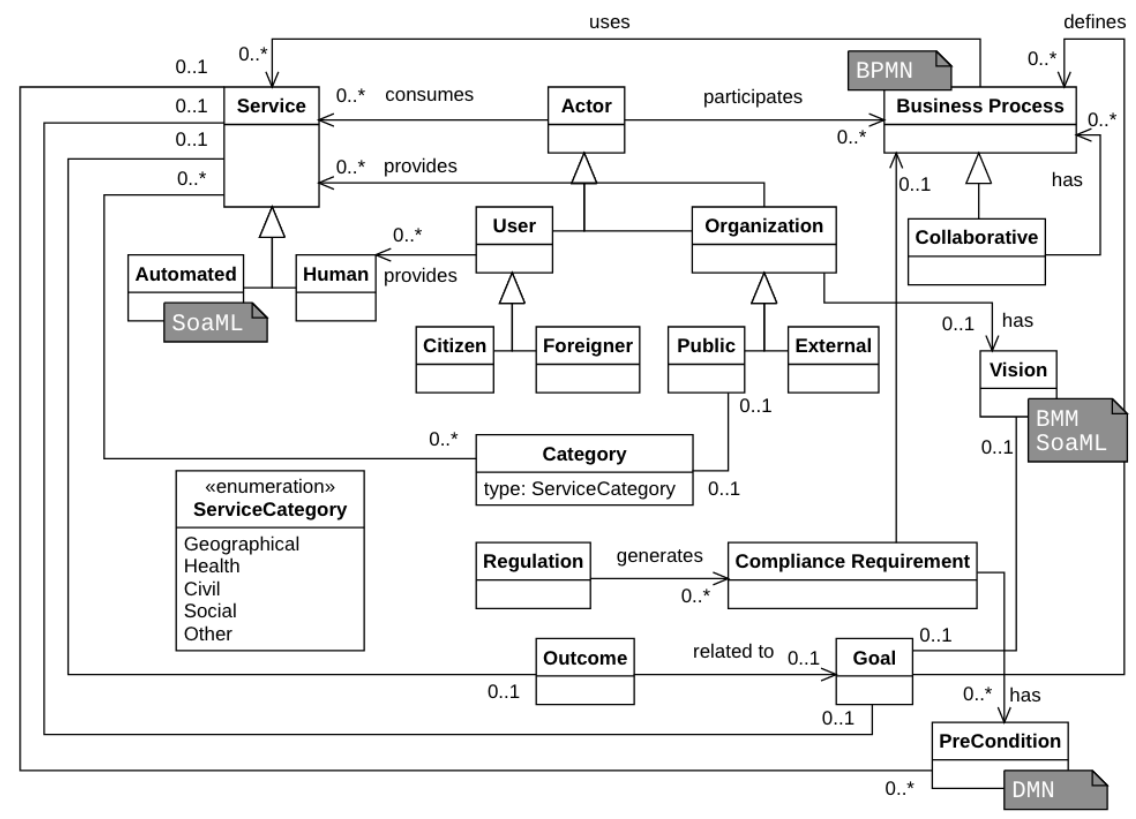

Figure 3. High-level e-government metamodel

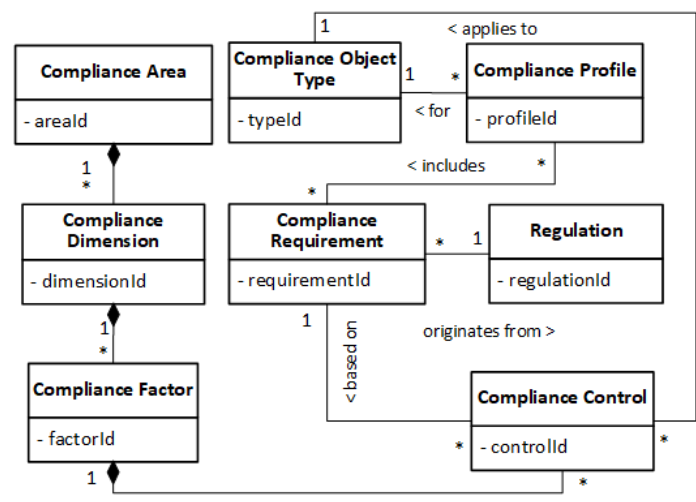

Figure 4. Compliance Requirements from [21]

some interesting context information is related to compliance requirements.

- Objective package represents characteristics of the collaborative network (common objective and facts that the collaboration has to manage). In our case, this package could be adapted to consider business aspects, as the vision of an organization and the goals that business processes pursue, which are connected with the e-government services actors provide.

- Behavior package contains concepts dedicated to describing collaborative behavior described as process models. The principle is to have a central pool, for a mediation system, in charge of the whole coordination schema, and one pool per actor to include their one activities, invoked by the mediation system. Besides the PDI does not coordinate the whole process, it mediates for the consumption of services within the collaborative scenarios. At first, this package may remain unchanged.

In [6] there is also proposed a fifth package (Performance) assessing the overall performance of the collaboration by comparing through dedicated Key Performance Indicators (KPIs) the performance objective to the measures on the field. This package could also be integrated with execution measures for the continuous improvement of business processes realized by services, as those already defined in [22].

\subsection{Generation of collaborative processes}

The modeling potential offered by the CORE metamodel extended with a specific e-Gov layer is the support for a facilitated e-Gov modeling activity. It means that modeling the e-Gov situation within a stable and actionable framework may be made easier thanks to the usage of this metamodel. However, modeling a system or a situation is not (and will never be) the ultimate purpose, it is only an initial or intermediary step to a broader objective. In the case of this article, the next objective is the modeling of a relevant collaborative process model. The crucial idea is the following: considering that the metamodel allows the user to obtain a formal and trustable 


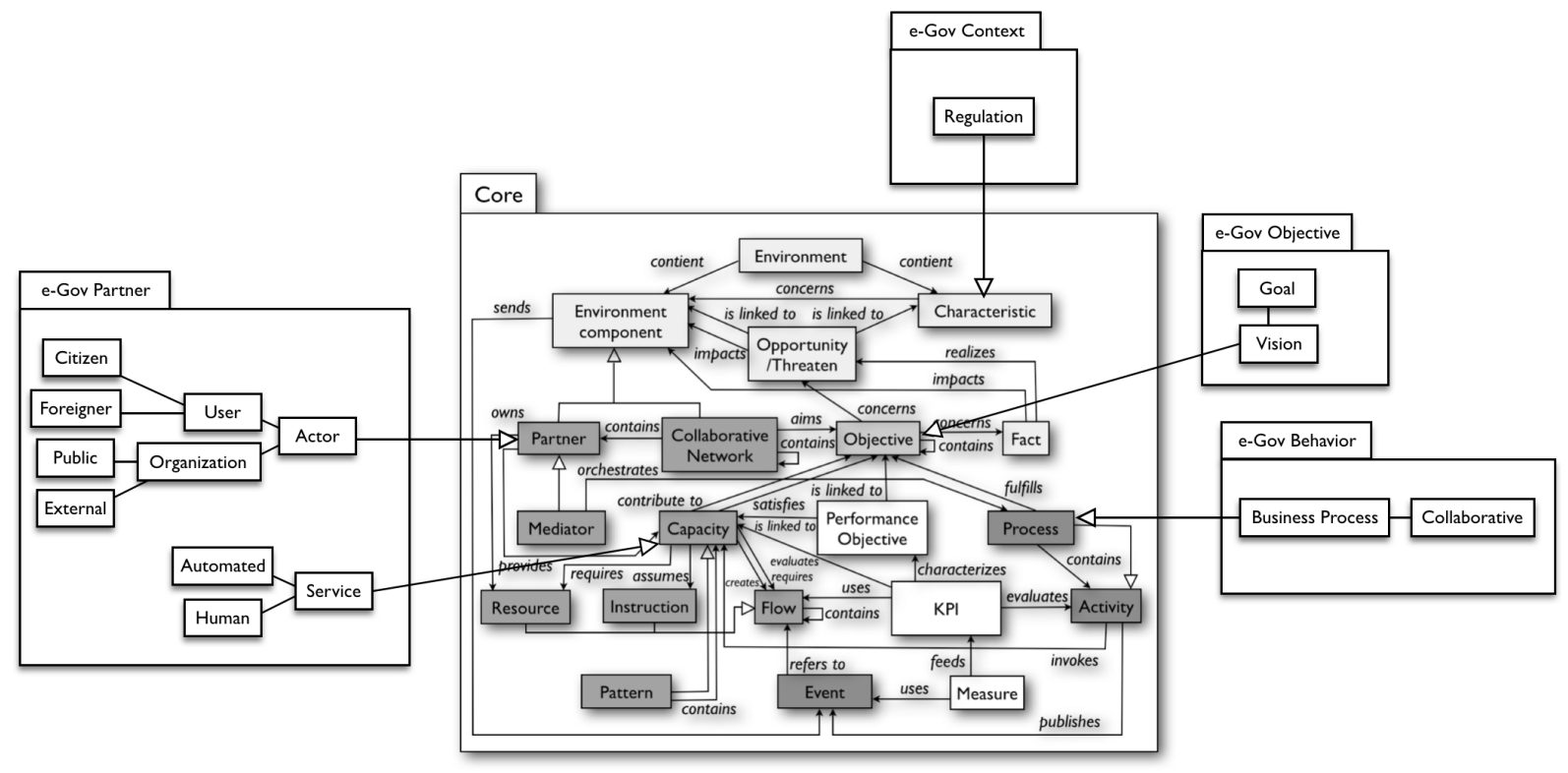

Figure 5. E-Government metamodel for collaborative processes

situational picture (of the observed e-Gov situation), the ambition is to exploit the obtained situational model to generate a collaborative process model that would, by construction, fit the considered situation. This model transformation principle has been presented in the context of industrial collaborations in [23] and the context of crisis management in [24]. The basic idea is to define model transformation rules that apply to concepts: in the case of the presence of any instance of concept A in the situation model, then, all rules defined for concept A will be applied specifically in this instance (this is also the case for rules related to combination of concepts). The aim is to use instances of concepts of the "partner", "objective" and "context" package to infer instances of the "behavior" package. On a more concrete point of view, the principles of the existing rules (at the CORE metamodel level) are the following:

- For each instance of "Objective" of the Objective package, all instances of "Capacity" with a "satisfy" connection (or "contribute to" if there is no "satisfy" connection) is extracted. Then, based on the highest coverage percentage, the best instance of satisfying "Capacity" is selected (or all instances of "Capacity" contributing to).

- In the Behavior package, one instance of "Activity" is created for every selected instance of "Capacity" (the given name is the same).

- An instance of "Process" is created that contains all instances of "Activity".

- Then, based on concept of the extended behavior, one single instance of the "Mediation IS Pool" is created and one instance of "Partner Pool" is created for every instance of "Partner" that actually has at least one instance of its "Capacity" that has been selected to create one instance of "Activity".

- All instances of "Activity" are placed in the instance of "Partner Pool" of their partner (the one that owns the instance of "Capacity" that created that instance of "Activity") while one instance of "MIS Task" is created for each instance of "Activity" with the name "invoke-Activity.name" and placed in the single instance of "Mediation IS Pool".

- Instance of "Start Event" and "End Event" are added.

- Note that the flows between instances of "Activity" (except for the ones between "ActivityA" and "invoke-ActivityA" respectively in a "Partner Pool" and in the "Mediation IS Pool", which are obvious instances of "message flow") are to be defined based on priority criteria from the user. Thus, the sequence or parallelism of instances of "activity" will be decided.

It is to notice that the model transformation mechanisms presented above are specific to the concepts of the CORE metamodel. One of the great benefits of the layer structure of the metamodel is that instances of concepts of the CORE metamodel will trigger associated rules, but and foremost, instances of concepts from a 
layer, inheriting from concepts of the CORE (no matter the length of the inheritance chain) will also trigger these rules. Besides, specific rules can complementary be defined for concepts of some layers (that will be specifically triggered by instances of these concepts and any instances of concepts below in the inheritance chain).

The previous basic principles of model transformation rules are efficient if and only if the instances of the "Objective", "Capacity" and "Partner" are correctly and sufficiently connected. However, it is absolutely to be considered that there may be a lack of connections between instances of these concepts. In such a case, and as presented in [25], the use of an accumulative knowledge base, populated with instances of the concepts of the metamodel (inherited from previous use-cases or a systematic study of domain-specific scenarios) could be used to make some indirect and transitive connection. For instance, an orphan instance of "Objective" (i.e., an instance of "Objective" without any instance of "Capacity" actually satisfying or contributing to) could be semantically and syntactically connected to existing instances of "Objective" within the Knowledge base.

Considering that these instances of "Objective" are certainly connected to instances of "Capacity" that satisfy or contribute to it, the next step is to use the same mechanism of semantic and syntactic reconciliation to detect, within the situation model, instances of "capacity" that are similar or close to these instances of "Capacity" from the knowledge base. The syntactic and semantic mechanisms used to perform this reconciliation have been presented in [26].

\section{Case study: Uruguayan e-Gov platform}

In Section 2.2 we introduced the Uruguayan e-government PDI, which is already in place and providing to citizens an inter-organizational service-based platform for enacting collaborative processes. In this context, two or more organizations may agree to carry out collaborative BPs by leveraging the operations of the services available on the platform. This section describes how one of these collaborative processes can be represented in terms of the e-government metamodel proposed in Section 3.1. This serves as a first validation (O4) of the model-driven perspective of the whole approach.

\subsection{Born Alive Collaborative BP}

The Born-Alive collaborative BP aims to provide newborn babies their national identification document (NID) as well as health coverage and social security benefits for their parents [8]. It is inspired by an existing (partially implemented) collaborative BP, but it was adjusted and simplified for this paper. The collaborative process involves various organizations such as MSP, DGREC, BPS, MIDES, and DNIC. Figure 6 presents the message exchanges within this process using a BPMN2 choreography diagram.

The collaborative BP starts after a baby is certified as "born-alive" in the maternity services, in which case a born alive certificate is issued by MSP. At this moment, MSP gets a provisional national identification number (NIN) from DNIC (Born Alive Certificate service) and informs AGESIC of the born-alive baby by publishing a citizen data update (Citizens Data Updates service). AGESIC informs DGREC, MIDES, and BPS of this update (Citizens Data News) so that the national civil records are updated in DGREC, the baby joins the Nationwide Integrated Healthcare System (SNIS) and parents can receive the applicable benefits (e.g., family allowance, maternity leave).

When parents request in person the NID for the baby in DNIC and the NID is issued, DNIC interacts with AGESIC (Procedure Status service) to inform this fact. Also, if AGESIC does not receive this notification during the ninety days after the provisional NIN was assigned, AGESIC cancels the provisional NIN by interacting with DNIC (Born Alive Certificate service) and informs MIDES, DGREC, and BPS of the update (Citizens Data News service). Table 1 presents a summary of the services as well as their operations involved in the Born Alive collaborative BP.

Table 1. Operations in Born Alive Collaboration

\begin{tabular}{|l|l|l|}
\hline Organization & Service & Operation \\
\hline DNIC & $\begin{array}{l}\text { Born Alive } \\
\text { Certificate }\end{array}$ & GetIdNumber \\
\cline { 3 - 3 } & CancelldNumber \\
\hline \multirow{2}{*}{ AGESIC } & $\begin{array}{l}\text { Citizens Data } \\
\text { Updates }\end{array}$ & PublishCitizenDataUpdate \\
\cline { 2 - 3 } & $\begin{array}{l}\text { Procedures } \\
\text { Status }\end{array}$ & NotifyProcedureStatus \\
\hline $\begin{array}{l}\text { BPS, MIDES, }, \\
\text { DGREC }\end{array}$ & $\begin{array}{l}\text { Citizens Data } \\
\text { News }\end{array}$ & NotifyCitizenDataUpdate \\
\hline
\end{tabular}

\subsection{Born alive process in e-Gov metamodel}

A partial representation of the Born Alive collaborative process using the proposed e-government metamodel is depicted in Figure 7.

Six organizations participate in the born alive process (i.e., DNIC, MSP, AGESIC, BPS, MIDES, and DGREC). These organizations provide and consume four different services (only three are shown). For example, DNIC provides the Born Alive Certificate service which is consumed by MSP and AGESIC. Organizations and services may be associated with 


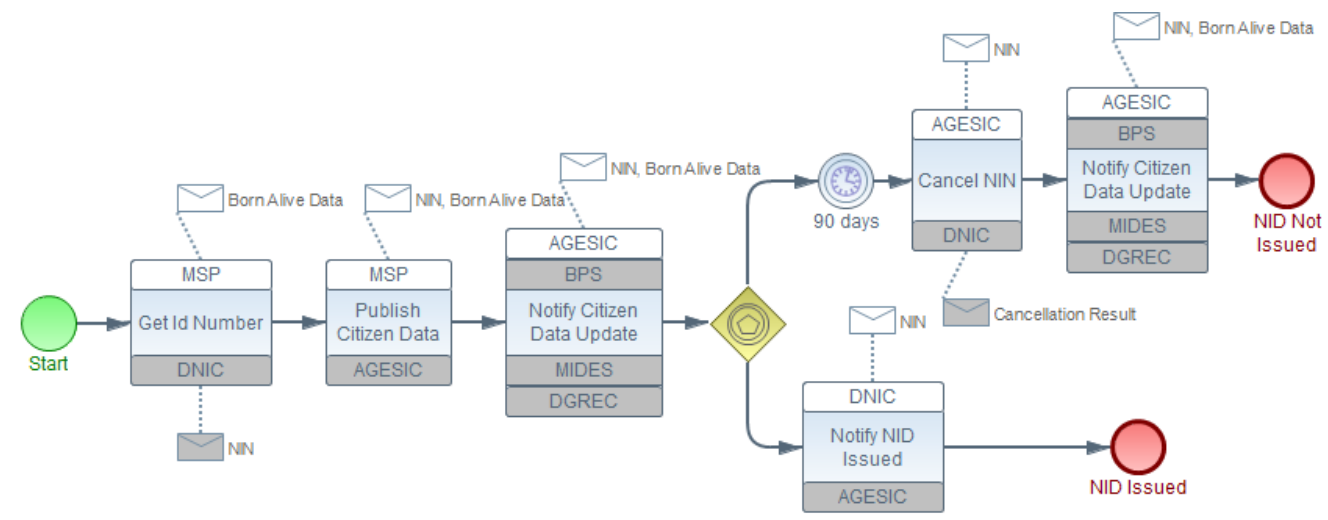

Figure 6. Born Alive Certificate choreography diagram in BPMN 2.0 from [10]

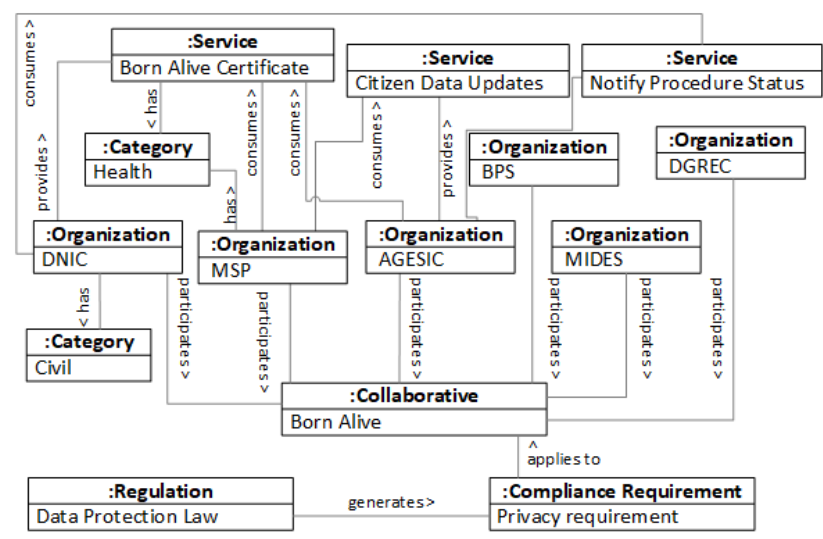

Figure 7. Collaborative BP in e-gov metamodel

categories which provide information regarding their area of operation and application, respectively. For instance, DNIC is associated with the Civil category and the Born Alive Certificate service is associated with the Health category.

Finally, business processes may have compliance requirements originating from different regulations. In this case, the Born Alive collaborative BP may have privacy requirements (originating from the Data Protection Law of Uruguay), which establish that an organization cannot share sensitive data of a citizen unless the citizen has provided the required consents.

As claimed before, this knowledge representation using the e-government metamodel is a first step towards the application of the proposed approach. Nevertheless, the metamodel provides a unified view for both technical and organizational aspects within an e-gov platform, as well as enables the generation of collaborative BP using this knowledge, even without the choreography specification (as described in Section 3.3).

In the context of this case study we envision that the knowledge representation shown in Figure
7 would enable the generation of the Born Alive collaborative BPs specification, even without knowing the choreography presented in Figure 6.

\section{Conclusions}

In this paper, we present advances of an ongoing research effort focused on the formalization and exploitation of e-government knowledge and information to improve the definition, automated generation, control, monitoring and improvement of e-government collaborative BPs.

Our main contribution is the integrated vision of already existing proposals from the partners. This vision is based on an e-government metamodel that aims to formalize key concepts and relations within the e-government domain. It can also be integrated with an existing core metamodel for collaborative processes, providing means for BPs discovery and conformance checking. Although the metamodel was motivated by the Uruguayan e-gov platform, it is general enough to be used within other contexts.

We also provided an initial validation of the advances by instantiating the metamodel for the "Born alive" collaborative BP. Although it is a single collaborative BP, it presents a basic structure that many e-government BPs present. This knowledge representation using the e-government metamodel is the first step towards the application of the approach. As described in Section 3.2, the approach enables the generation of collaborative BP using this knowledge, even without the choreography specification.

In that sense, we are working on integrating the metamodel within the existing tools and platforms to use it along with execution information from the interoperability platform, to generate e-government collaborative BPs that can help organizations gain insight into them, and automate them in the selected 
platform. Also, from the BPs compliance point of view, we are working on performing post mortem analysis on traceability information to check whether key policies have been violated or not.

\section{Acknowledgements}

This work was funded by STIC-AmSud project "MOPAIOSIP" in CFP 2017 (execution 2018-2020).

\section{References}

[1] A. Delgado, L. González, and D. Calegari, "Towards setting up a collaborative environment to support collaborative business processes and services with social interactions," in Service-Oriented Computing - ICSOC 2017 Workshops and Satellite Events, Revised Selected Papers, pp. 308-320, 2017.

[2] M. Dumas, M. L. Rosa, J. Mendling, and H. Reijers, Fundamentals of Business Process Management. Springer, 2013.

[3] M. Weske, Business Process Management - Concepts, Languages, Architectures, 2nd Edition. Springer, 2012.

[4] OMG, "Business process model and notation (BPMN) v2.0," tech. rep., OMG, 2011.

[5] A. Delgado, F. Ruiz, and I. G. R. de Guzmán, "A reference model-driven architecture linking business processes and services," in 51st Hawaii International Conference on System Sciences, HICSS 2018, pp. 1-10, 2018.

[6] F. Bénaben, M. Lauras, S. Truptil, and N. Salatgé, "A metamodel for knowledge management in crisis management," in 49th Hawaii International Conference on System Sciences, HICSS 2016, pp. 126-135, IEEE Computer Society, 2016.

[7] F. Bénaben, A. Montarnal, S. Truptil, M. Lauras, A. Fertier, N. Salatgé, and S. Rebiere, "A conceptual framework and a suite of tools to support crisis management," in 50th Hawaii International Conference on System Sciences, HICSS 2017, pp. 1-10, IEEE Computer Society, 2017.

[8] R. Ruggia, A. Delgado, J. Abin, L. González, and P. Garbusi, "Managing consistency in e-government transactions," in Proceedings of the 9th International Conference on Theory and Practice of Electronic Governance - ICEGOV '15-16, ACM Press, 2016.

[9] L. González, R. Ruggia, J. Abin, G. Llambías, R. Sosa,

B. Rienzi, D. Bello, and F. Álvarez, "A service-oriented integration platform to support a joined-up e-government approach: The uruguayan experience," in Advancing Democracy, Government and Governance, vol. 7452 of Lecture Notes in Computer Science, pp. 140-154, Springer Berlin Heidelberg, 2012.

[10] L. González, "A comprehensive and policy-based approach to compliance management within inter-organizational service integration platforms. PhD. Thesis," tech. rep., Universidad de la República, Uruguay, 2019.

[11] F. Pirri, M. Paolucci, D. Chini, M. C. Pettenati, and S. Innocenti, "Interdatanet: Interoperability framework to support collaborative creation and management of official documents in e-government processes," in 41st Hawaii International International Conference on Systems Science (HICSS-41), Proc., p. 193, IEEE Computer Society, 2008.

[12] C. Navarrete, J. R. Gil-García, S. Mellouli, T. A. Pardo, and H. J. Scholl, "Multinational e-government collaboration, information sharing, and interoperability: An integrative model," in 43rd Hawaii International International Conference on Systems Science (HICSS-43), Proc., pp. 1-10, IEEE Computer Society, 2010.

[13] R. Helali, I. Achour, L. Labed Jilani, and H. Ben Ghezala, "A study of e-government architectures," in E-Technologies: Transformation in a Connected World, pp. 158-172, Springer Berlin Heidelberg, 2011.

[14] P. Beynon-Davies, "Models for e-government," Transforming Government: People, Process and Policy, vol. 1, no. 1, pp. 7-28, 2007.

[15] P. Salhofer, B. Stadlhofer, and G. Tretter, "Ontology driven e-government," Electronic Journal of e-Government, vol. 7, no. 4, pp. 415-424, 2009.

[16] K. Hinkelmann, B. Thönssen, and D. Wolff, Ontologies for E-government, pp. 429-462. Springer Netherlands, 2010.

[17] R. M. de Araujo, Y. Taher, W. van den Heuvel, and C. Cappelli, "Evolving government-citizen ties in public service design and delivery," in Electronic Government and Electronic Participation: Joint Proceedings of Ongoing Research of IFIP EGOV and IFIP ePart, vol. 221 of $L N I$, pp. 19-26, GI, 2013.

[18] OMG, "Service oriented architecture modeling language (SoaML) v1.0.1," tech. rep., OMG, 2012.

[19] OMG, "Business motivation model (BMM) v1.3," tech. rep., OMG, 2015.

[20] OMG, "Decision model and notation (DMN) v1.1," tech. rep., OMG, 2016.

[21] L. González and R. Ruggia, "A comprehensive approach to compliance management in inter-organizational service integration platforms," in Proceedings of the 13th International Conference on Software Technologies, ICSOFT 2018, pp. 722-730, SciTePress, 2018.

[22] A. Delgado, B. Weber, F. Ruiz, I. G. R. de Guzmán, and M. Piattini, "An integrated approach based on execution measures for the continuous improvement of business processes realized by services," Information \& Software Technology, vol. 56, no. 2, pp. 134-162, 2014.

[23] W. Mu, F. Benaben, and H. Pingaud, "Collaborative process cartography deduction based on collaborative ontology and model transformation," Information Sciences, vol. 334, pp. 83-102, 2016.

[24] M. Lauras, S. Truptil, and F. Benaben, "Towards a better management of complex emergencies through crisis management metamodeling," Disasters, vol. 39, no. 4, pp. 687-714, 2015.

[25] F. Benaben, N. Boissel-Dallier, A.-M. Barthe, S. Zribi, and H. Pingaud, "Supporting interoperability of collaborative networks through engineering of a service-based mediation information system (mise 2.0)," Enterprise Information System, vol. 9, no. 5-6, pp. 556-582, 2015.

[26] T. Wang, S. Truptil, and F. Benaben, "An automatic model-to-model mapping and transformation methodology serving to model-based system engineering," Information Systems and e-Business Management, vol. 15, no. 2, pp. 323-376, 2017. 